\title{
Autophagy inhibition enhances pan-Bcl-2 inhibitor AT-101-induced apoptosis in non-small cell lung cancer
}

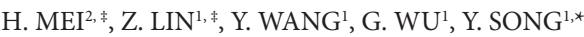 \\ ${ }^{1}$ Cancer Center; ${ }^{2}$ Department of Pediatric Surgery, Union Hospital, Tongji Medical College, Huazhong University of Science and Technology, \\ Wuhan, China \\ ${ }^{*}$ Correspondence: unionlinsong@gmail.com \\ ${ }^{*}$ Contributed equally to this work.
}

Received June 21, 2013 / Accepted August 9, 2013

\begin{abstract}
Overexpression of anti-apoptotic $\mathrm{Bcl}-2$ proteins is commonly observed in a variety of cancers and associated with resistance to conventional chemotherapeutic drugs. Targeting multiple anti-apoptotic proteins is now possible with the small molecule $\mathrm{BH} 3$ domain mimetics such as AT-101. Autophagy has been found to function as a resistance mechanism against apoptotic cell death. In this study, we investigated the role of autophagy in the AT-101-induced apoptotic death of human lung cancer cells. It was found that AT-101 dose-dependently induced both apoptosis and autophagy in A549 lung cancer cells. And the apoptotic cell death induced by AT-101 was greatly enhanced after autophagy inhibition. Our findings demonstrated that AT-101-induced autophagy was cytoprotective rather than being part of cell death process in lung cancer cells. Inhibition of autophagy in combination with efforts to enhance apoptosis through targeting the Bcl-2 family of proteins may be a promising strategy to overcome drug resistance.
\end{abstract}

Key words: apoptosis, autophagy, BH3, lung cancer

Non-small cell lung cancer (NSCLC) accounts for 75\% of all lung cancers and even with improved diagnostic approaches and introduction of novel treatments in the past decades, the median 5 -year overall survival is still only 15 months [1]. The $\mathrm{Bcl}-2$ family plays a critical role in determining the susceptibility of cells to apoptosis, and its overexpression has been shown to be associated with drug resistance to various categories of chemotherapeutic agents [2-4]. Elevated Bcl-xL and Bcl-2 levels have also been observed in non-small cell lung cancer [5, 6]. Gossypol, a natural $\mathrm{BH} 3$-mimetic compound, is currently found to be able to bind to the $\mathrm{BH} 3$ domains of $\mathrm{Bcl}-2, \mathrm{Mcl}-1$, and Bcl-xL and exhibit anti-carcinogenic effects toward a wide variety of cancers both in vitro and in vivo [7-9].

Autophagy is a major intracellular mechanism for the degradation and recycling of proteins, ribosomes, and entire

\footnotetext{
Abbreviations: mTOR, mammalian target of rapamycin; NSCLC, non-small cell lung cancer; MOM, mitochondrial outer membrane; ATG, autophagy-related genes; $\mathrm{BH} 3, \mathrm{Bcl}-2$ homology domain 3; Bcl-2, B-cell lymphoma-2; Bcl-xL, B-cell lymphoma-extra large; Mcl-1, myeloid cell leukemia1; LC3, light chain 3; GFP, green fluorescent protein.
}

organelles. Under normal condition, autophagy functions to maintain internal homeostasis by eliminating unnecessary or excessive proteins and injured or aged organelles. Meanwhile, autophagy is also found in some pathological conditions, including myopathy, neuronal degeneration, infectious disease, and cancer [10]. Because BH3-mimetic compound can induce autophagy through binding to the $\mathrm{BH} 3$-binding groove of $\mathrm{Bcl}-2$ or $\mathrm{Bcl}-\mathrm{xL}$ and releasing Beclin1, its role in autophagy has drawn more attention [11-13].

In this study, we focused on the investigation of the role of autophagy induced by AT-101 (R-(-)-gossypol acetic acid) in non-small cell lung cancer (NSCLC). AT-101 is a natural $\mathrm{BH} 3$ mimetic small molecule binding to the $\mathrm{BH} 3$ domains of $\mathrm{Bcl}-2, \mathrm{Bcl}-\mathrm{xL}$, and $\mathrm{Mcl}-1$, which has been reported recently to induce apoptosis in multiple cancer cell lines with high levels of Bcl-2 and/or Bcl-xL [7-9]. We demonstrated that AT-101 induced apoptosis and autophagy in A549 lung cancer cell line, and provided evidence for the first time that inhibition of autophagy enhanced the apoptosis induced by AT-101. 


\section{Material and methods}

A549 lung cancer cell line was purchased from American Type Culture Collection (ATCC; Manassas, VA, USA) and cultured in RPMI1640 medium (Invitrogen) supplemented with $10 \%$ fetal bovine serum and $1 \%$ penicillin-streptomycin in a $\mathrm{CO}_{2}$ incubator $\left(37^{\circ} \mathrm{C}, 5 \% \mathrm{CO}_{2}\right)$. Antibodies against $\mathrm{Bcl}-\mathrm{xL}$, Bcl-2, Mcl-1, ATG5, ATG7, Beclin 1, microtubule-associated protein 1 light chain 3 (LC3) and p-mTOR (S2448), p-S6K (T389) and p-4EBP1 (Thr37/46) were obtained from Cell Signaling. Monoclonal anti $\beta$-actin and secondary antibodies were purchased from Santa Cruz Biotechnology. Z-VADFMK and wortmannin were obtained from Sigma. AT-101 was provided by Ascenta Therapeutics. Stock solution was prepared in $100 \%$ dimethyl sulfoxide (DMSO) and stored at $-20^{\circ} \mathrm{C}$. The drug was diluted in fresh medium before each experiment. The siRNAs to ATG5, ATG7 and control siRNA were obtained from Qiagen.

Apoptosis assay. A549 cells $\left(5 \times 10^{5} /\right.$ well $)$ were plated in a six-well plate. After overnight incubation, cells were treated with DMSO or different concentrations of AT-101 combined with $20 \mu \mathrm{M}$ Z-VAD-FMK for 48 hours. Apoptotic events were evaluated by annexin V labeling using Annexin V-FITC apoptosis detection kit (BD Pharmingen) according to the manufacture's instruction.

Western blot. After treatment with AT-101, A549 cells were collected and underwent lysis in lysis buffer $(50 \mathrm{mM}$ HEPES, $150 \mathrm{mM} \mathrm{NaCl}, 10 \%$ glycerol, $1 \%$ Triton X-100, $1.5 \mathrm{mM} \mathrm{MgCl}, 1 \mathrm{mM}$ ethylene glycol tetraacetic acid, $1 \mathrm{mM}$ sodium vanadate, $10 \mathrm{mM}$ sodium pyrophosphate, $10 \mathrm{mM}$ $\mathrm{NaF}, 300 \mu \mathrm{M}$ p-nitrophenyl phosphate, $1 \mu \mathrm{g} / \mathrm{mL}$ leupeptin, $1 \mathrm{mM}$ phenylmethanesulfonylfluoride, $10 \mu \mathrm{g} / \mathrm{mL}$ aprotinin, $\mathrm{pH}$ 7.3). Western blot was conducted in $12 \%$ and $8 \%$ sodium dodecyl sulfate polyacrylamide gels. After the completion of electrophoresis, the gels were transferred to the nitrocellulose membrane, and blocked with $5 \%$ nonfat dry milk in phosphate buffered saline-Tween 20 for one hour at room temperature. The membranes were incubated with the primary antibodies overnight at $4^{\circ} \mathrm{C}$. After washing with TBST three times, the membranes were incubated with the secondary antibodies for one hour and subjected to Western blot analysis with ECL detection reagent (Millipore).

Quantitative Real Time-PCR. Total RNA isolated from the cells using RNeasy kit (Qiagen) was reverse-transcribed using oligo (dT) and Superscript II RT (Invitrogen) and the resulting CDNA was used for PCR amplification using gene-specific primer pairs. PCR conditions for these reactions were as follows: $95^{\circ} \mathrm{C}, 10 \mathrm{~s} ; 58^{\circ} \mathrm{C}, 30 \mathrm{~s} ; 72{ }^{\circ} \mathrm{C} 10 \mathrm{~s}$ for 40 cycles. Bio-Rad iQ5 multicolor PCR detection system and iQ5 optical system software analysis were used for quantifying gene expression (Bio-Rad, version 2.0). The expression levels of ATG5 and ATG7 were normalized to GAPDH. The primers used for real time PCR were as follows: ATG5 forward: TTC AAT CAG GTT TGG TGG AGG C and reverse: ATG GCA GTG GAG GAA AGC AGA G; ATG7 forward: ATG CCT GGG CAT CCA
GTG AAC TTC and reverse: CAT CAT TGC AGA AGT AGC AGC CA; GAPDH forward: GGA GTC AAC GGA TTT GGT and reverse: GTG ATG GGA TTT CCA TTG AT.

GFP-LC3 analysis. A549 Cells were transfected with GFPLC3 vector using Lipofectamine 2000 (Invitrogen). After $24 \mathrm{~h}$, cells were treated with DMSO (control) or AT101 $(15 \mu \mathrm{M})$ for $48 \mathrm{~h}$, and then fixed in $4 \%$ formaldehyde for $10 \mathrm{~min}$. Cells were then washed twice with PBS and stained with DAPI, and observed under a fluorescence microscope.

Immunoprecipitation. A549 cells $\left(5 \times 10^{6}\right)$ were treated with AT-101 $(15 \mu \mathrm{M})$ or DMSO for $48 \mathrm{~h}$ and lysed in CHAPS lysis buffer (20 mM Tris ( $\mathrm{pH} 7.4$ ), $137 \mathrm{mM} \mathrm{NaCl}, 2 \mathrm{mM}$ EDTA, $10 \%$ glycerol, and $2 \%$ CHAPS) for $3 \mathrm{~h}$ at $4{ }^{\circ} \mathrm{C}$. The cleared lysates were subjected to immunoprecipitation with anti-Beclin 1 antibody and protein G-Sepharose. The immunoprecipitates were then analyzed by Western blotting using antibodies against Bcl-xL, Beclin 1 and LC3.

RNA interference. A549 cells $\left(5 \times 10^{5} /\right.$ well $)$ were plated in six-well plates and transfected with siRNA by Lipofectamine 2000 according to the manufacturer's manual. AT-101 was added to the cells $24 \mathrm{~h}$ after transfection. Cells were then incubated for $48 \mathrm{~h}$ prior to western blot or apoptosis assay.

Statistical analysis. Statistical analysis of the differences between the groups was performed using Student's $t$ test. Probability values of less than 0.05 were considered statistically significant.

\section{Results}

AT-101 induced apoptosis and autophagy in A549 lung cancer cells. It has been showed that AT-101 can exhibit proapoptotic effect in a wide variety of cancer types both in vitro and in vivo. To assess the effect of AT-101 on lung cancer cells, A549 cells were treated with different concentrations of AT-101 or AT-101 combined with a pan-caspase inhibitor Z-VADFMK (Z-VAD) for $48 \mathrm{~h}$ and analyzed with Annexin V assay. As shown in Figure. 1A, the number of AT-101-induced apoptotic cells was significantly increased in a dose-dependent manner compared with that of untreated cells. Bcl-xL is a major antiapoptotic protein in the Bcl-2 family whose overexpressions is more widely observed in human lung cancer cells than that of Bcl-2 and Mcl-1 [5]. To further investigate the potential mechanism of AT-101-induced apoptosis, cells treated with AT-101 were subjected to immunoblottings using antibodies against Bcl-xL, Bcl-2 and Mcl-1. AT-101 treatment of A549 cells resulted in a dose-dependent downregulation of $\mathrm{Bcl}-\mathrm{xL}$ expression, while the protein levels of Bcl-2 and Mcl-1 remained constant (Fig 1B).

We next explored the activation of autophagy in A549 cells by AT-101. The conjugation of cytoplasmic protein LC3 to phosphatidylethanolamine is a characteristic marker of autophagy, resulting in the formation of LC3-II, a form that localizes to the presautophagosomal and autophagosomal membranes. In response to autophagy, the conversion of LC3-I into LC3-II before and after AT-101 treatment was 
A

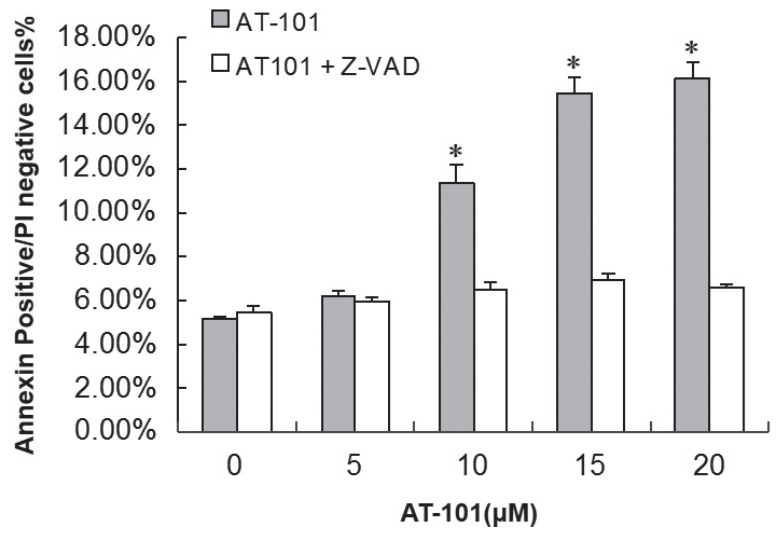

B

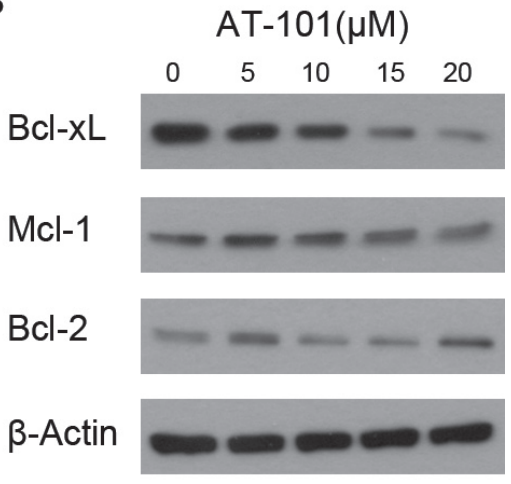

Figure 1. AT-101 induced apoptosis in A549 cells. (A) Effect of AT-101 on apoptotic cell death in A549 cells. Cells were treated with DMSO or different concentrations of AT-101 or combined with Z-VAD $(20 \mu \mathrm{M})$ for $48 \mathrm{~h}$. Results are means \pm SD of three independent experiments. ${ }^{\star} \mathrm{P}<0.05$ between $\mathrm{AT}$ 101 and AT-101+ Z-VAD in indicated groups. (B) AT-101 down-regulated Bcl-xL expression in A549 cells. Cells were treated with DMSO or different concentrations of AT-101 for $48 \mathrm{~h}$ respectively. Lysates were prepared and subjected to immunoblotting analysis with indicated antibodies.

determined by western blotting. It was found that AT-101 could also induce the switch of LC3-I to LC3-II in a dose dependent manner in A549 cells, indicating the activation of autophagy (Fig. 2A). We next examined the effects of AT-101 on the expression of ATG5 and ATG7, two critical proteins in regulating the formation of autophagosomes. AT-101 treatment increased the protein expressions of ATG5 and ATG7. However, there were no difference between the treatment and control group for the mRNA expression level, the result of which may be due to post-transcription mechanism (Fig. 2B). The cellular localization of LC3 can also be evaluated by stably transfected cells using the fluorescent autophagy marker GFP-LC3. As illustrated in Fig. 2C, AT-101 induced an accumulation of a punctuate fluorescent pattern, indicating the redistribution of LC3 to autophagic structures, whereas untreated cells displayed diffuse staining, confirming once again that AT-101 induced autophagy in A549 cells.

Previous studies have shown that the anti-apoptotic proteins like $\mathrm{Bcl}-\mathrm{xL}$ or $\mathrm{Bcl}-2$ down-regulated autophagy by binding to Beclin 1. And $\mathrm{BH} 3$ mimetic molecules can induce dissociation of the Beclin 1-Bcl-2/Bcl-xL complex to induce autophagy [15]. Since Bcl-xL expression was down-regulated after AT-101 treatment in A549 cells, we therefore wanted to investigate the effect of AT-101 on the dissociation of Beclin 1 and Bcl-xL. Co-immunoprecipitation experiments showed that when AT-101 induced autophagy, dissociation of the Beclin 1-Bcl-xL complex was also observed in A549 cells (Fig. 2D). Taken together, these data suggested that AT-101 might induce autophagy by disrupting the Beclin 1-Bcl-xL complex in A549 cells.

AT-101-induced autophagy in A549 cells is associated with inhibition of mTOR pathway. Autophagy is a complex process that is regulated by multiple protein complexes. Sev- eral studies revealed that $\mathrm{BH}-3$ mimetics could also stimulate other pro-autophagic signal-transduction pathways $[16$, 17]. The mTOR complex 1 (mTORC1) controls initiation of autophagy upstream of the ULK1 (uncoordinated-51-like kinase 1, the mammalian ATG1 orthologs) complex. Activation of mTORC1 downregulates autophagy and is responsible for the phosphorylation of $4 \mathrm{E}-\mathrm{BP} 1$ and the p70S6K, two proteins involved in protein synthesis. Phosphorylation of mTOR, 4E-BP1 and p70S6K in A549 were significantly reduced by AT-101(Fig. 3). These findings showed that AT-101-induced autophagy might also be associated with mTORC1 inhibition.

Inhibition of autophagy potentiates AT-101-mediated apoptotic cell death. A growing body of evidence implicates that autophagy can serve as a protective response against tumor cells death. Therefore, to determine the effect of inhibition of autophagy on the cytotoxic effect of AT-101, A549 cells were treated with AT-101 $(15 \mu \mathrm{M})$ with and without a chemical autophagy inhibitor wortmannin (100 nM) for $48 \mathrm{~h}$. Treatment with wortmannin attenuated the levels of LC3 II, ATG5 and ATG7 induced by AT-101 (Fig. 4A). Moreover, co-treatment of AT-101 and wortmannin significantly potentiated AT-101 mediated apoptotic cell death in A549 cells, whereas wortmannin alone caused minimal apoptosis (Fig. 4B). In order to exclude the non-specific effect of Wortmannin, we knocked down the expression of the autophagy essential genes ATG5 and ATG7 using specific siRNAs. Autophagy was also suppressed by knockdown of the autophagic proteins ATG5 or ATG7 (Fig. 4C). Consistent with the pharmacological inhibition of autophagy, the down-regulation of ATG5 or ATG7 expression also significantly enhanced the apoptotic cell death induced by AT-101, confirming that AT-101-activated autophagy is cytoprotective (Fig. 4D). 

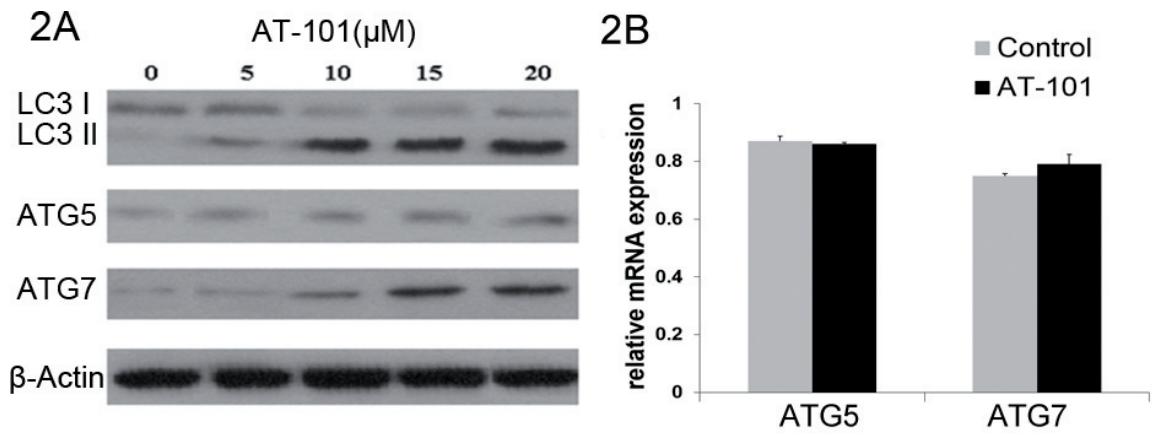

$2 \mathrm{C}$

2D
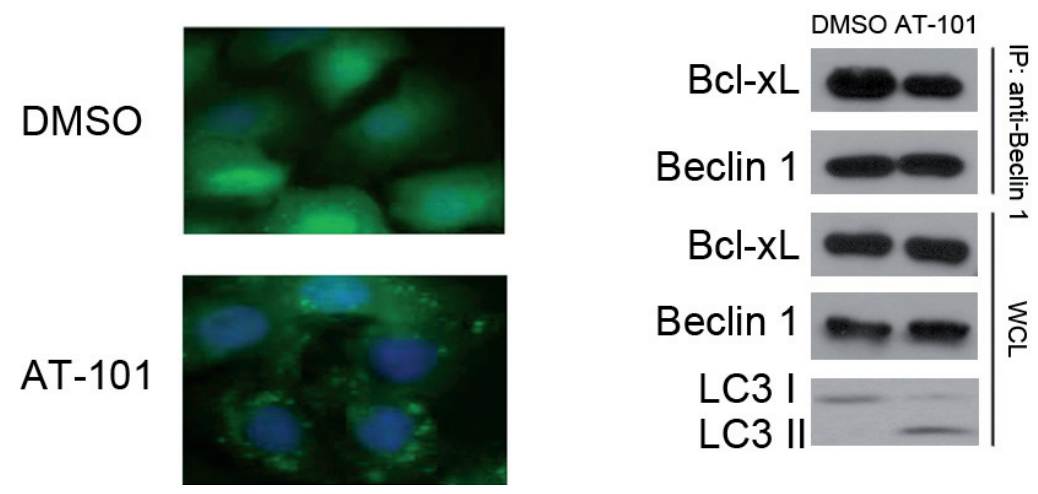

Figure 2. AT-101 triggered autophagy in A549 cells. (A) AT-101 dose-dependently induced the formation of LC3 II and increased the expressions of ATG5 and ATG7. (B) Quantitative Real time RT-PCR analysis of expressions of autophagy genes. A549 cells were treated with $15 \mu \mathrm{M}$ AT-101 for $48 \mathrm{~h}$ and the mRNA levels of ATG5/7 were measured. (C) Punctate pattern of GFP upon AT-101 treatment. A549/GFP-LC3 cells were treated with DMSO or AT-101 $(15 \mu \mathrm{M})$ for 48 hours, and then visualized by fluorescent microscopy. (D) AT-101 induced Beclin 1-Bcl-xL complex dissociation in A549 cells. Cells were treated with DMSO or $15 \mu \mathrm{M}$ AT-101 for 48h. Endogenous Beclin 1 or Bcl-xL was immunoprecipitated using goat polyclonal anti-Beclin 1 antibody (1:40 dilution) and subjected to immunoblotting using indicated antibodies.

\section{Discussion}

The current standard therapies of cancer largely depend on anti-proliferative signals triggered by drug- or radiationinduced DNA damage $[18,19]$. Despite recent advances for introduction of target drugs, the vast majority of cancers develop resistance. Advanced NSCLC is such an example of a highly prevalent cancer with poor prognosis. Cytotoxic chemotherapies produce objective remissions only in a minority of cases. Consequently, the development of novel therapies is urgently required, and will be facilitated by a detailed understanding of molecular effector and resistance mechanisms. During the past decade apoptosis signaling has received much attention as a potential target for cancer therapies. It has been found that the permeabilization of the mitochondrial outer membrane (MOM) regulated by the $\mathrm{BCl}-2$ family proteins is a critical step in apoptotic signal transduction [20]. Hence, targeting $\mathrm{BCl}-2$ proteins constitutes a new promising approach to cancer therapy.

Anticancer drugs take effects mainly by triggering cell cycle arrest and apoptotic or nonapoptotic cell death. Apoptosis
$\operatorname{AT}-101(\mu M)$

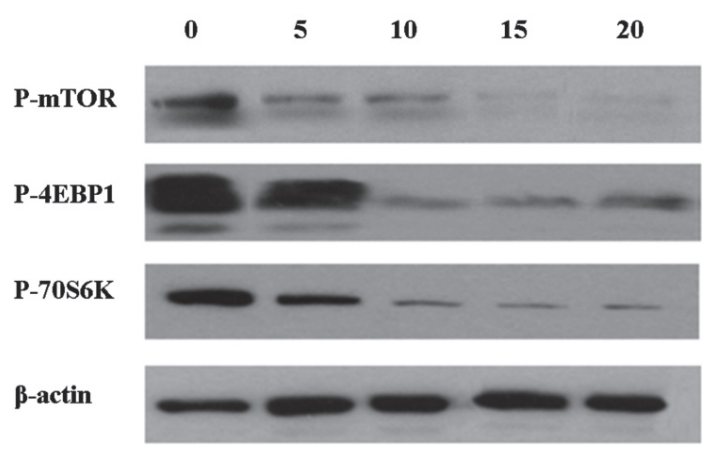

Figure 3. Autophagy induced by AT-101 was associated with inhibition of mTOR pathway in A549 cells. Cells treated with varying concentrations of AT-101 for $48 \mathrm{~h}$ were detected by western blotting.

is an active cell death executed by the activation of caspase family of proteases. DNA damage and anticancer drugs can activate caspases primarily via the "mitochondrial" pathway, 
4A

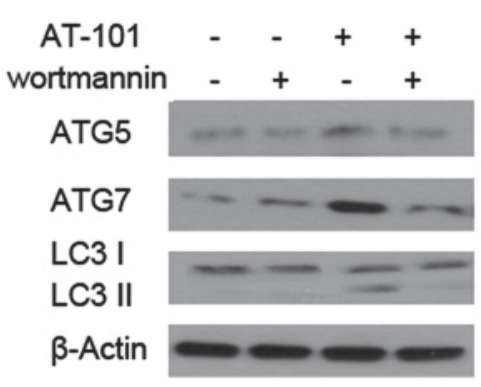

4C

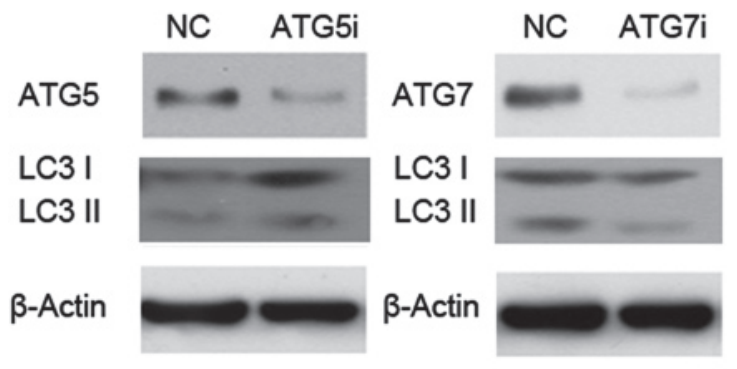

4B

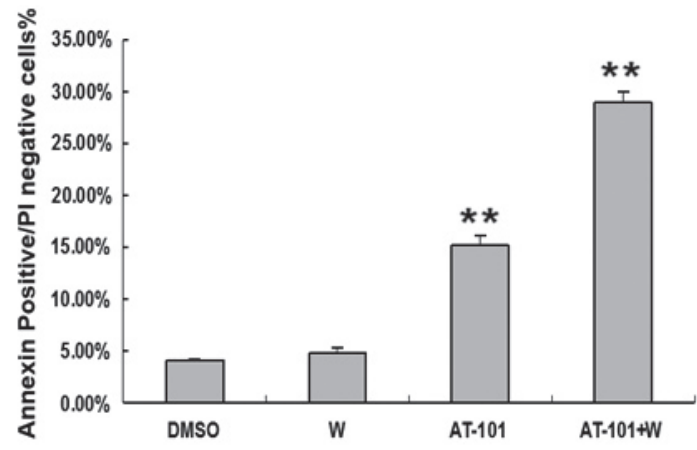

4D

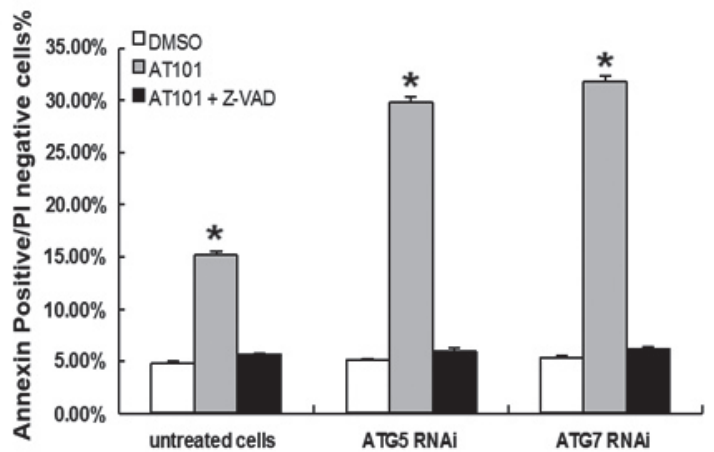

Figure 4. Inhibition of autophagy enhances the cytotoxity of AT-101 in A549 cells. (A) Treatment with wortmannin attenuated the levels of LC3 II, ATG5 and ATG7 induced by AT-101. A549 cells were cultured with DMSO or AT-101(15 $\mu \mathrm{M})$ for 48h alone or in combination with wortmannin $(100 \mathrm{nM})$ and subjected to immunoblotting analysis. (B) Apoptotic cell death was enhanced by an autophagy inhibitor. A549 cells were cultured with DMSO or AT-101 $(15 \mu \mathrm{M})$ for $48 \mathrm{~h}$ alone or in combination with wortmannin $(100 \mathrm{nM})$ followed by $\mathrm{PI}$ and Annexin- $\mathrm{V}$ staining. ${ }^{*} \mathrm{P}<0.05$ versus DMSO-treated control. (B) A549 Cells were transiently transfected with either control siRNA or siRNA specific to ATG5 and ATG7. (C) After overnight culture, transfected cells were treated with DMSO, AT-101(15 $\mu \mathrm{M})$, or AT-101 combined with Z-VAD $(20 \mu \mathrm{M})$ for $48 \mathrm{~h}$ followed by PI and Annexin-V staining. ${ }^{\star} \mathrm{P}<0.05$ between AT-101 and AT-101 $+\mathrm{Z}$-VAD in indicated groups.

which is regulated by the Bcl-2 protein family [21]. The Bcl-2 family proteins comprise both pro-apoptotic and anti-apoptotic members. Anti-apoptotic family members such as Bcl-2, Bcl-xL and Mcl-1 contain four Bcl-2 homology domains (designated $\mathrm{BH} 1-4)$ and can prevent apoptosis by repressing essential proapoptotic proteins that contain multiple Bcl-2 homology domains (BH1-2-3), like BAX or BAK. While another group of proapoptotic $\mathrm{Bcl}-2$ proteins containing only the $\mathrm{BH} 3$ domain (BH3-only), such as BIM, BID, PUMA or NOXA, can liberate the $\mathrm{BH} 1-2-3$ proteins and then permeabilize the MOM to release cytochrome $\mathrm{c}$ and additional apoptogenic factors into the cytoplasm to active the apoptosis $[22,23]$. Preclinical models have revealed that functional defects in apoptotic signal transduction were associated with drug resistance of cancer, and constitutively overexpression of inhibitors of apoptosis as well as inactivation of apoptosis promoters commonly observed in human cancers [23-25]. Accordingly, novel therapies targeting the apoptotic machinery bear high hopes for the management of cancers resistant to conventional treatments.
Clinical studies utilizing Bcl-2 antisense oligonucleotides have also been reported in different cancers (26-28). In addition, an alternative approach to antisense strategies is to develop small molecule inhibitors of pro-survival Bcl-2 family. Currently, AT-101 is being evaluated in phase I and II clinical trials for use as a single agent in B-cell malignancies and prostate cancer and in combination with other antitumor agents in a variety of hematologic, lymphoid, and solid tumors. More promising results were achieved in a Phase I/II trial, evaluating AT-101 in prostate cancer [3] and when AT-101 was administered in combination with docetaxel, in a Phase II trial of non-small cell lung cancer [29]. As a BH3 mimetic, it has been shown to inhibit $\mathrm{Bcl}-2, \mathrm{Bcl}-\mathrm{xL}$, and $\mathrm{Mcl}-1$ and reverse apoptosis resistance. Bcl-xL is widely expressed in both SCLC and NSCLC cells [5] and also plays important roles in the crosstalk between apoptosis and autophagy. In this study, we demonstrated that AT-101 induced apoptosis in a dose-dependent manner in A549 cells through down-regulation of $\mathrm{Bcl}-\mathrm{xL}$, indicating its potential role as a novel anticancer drug in NSCLC. 
Although $\mathrm{BH} 3$ mimetics were originally designed to stimulate apoptosis, their potential role as inducer of autophagy has recently come to light. Autophagy, designated as type II programmed cell death, is a catabolic process by which cells degrade intracellular components in vesicles. However, autophagy also functions as a pro-survival mechanism under unfavorable conditions such as deprivation of amino acids or ATPs, indicating a new role of autophagy in cancer development. Previous researches showed that gossypol could induce autophagy by liberating Beclin 1 from its inhibition by $\mathrm{Bcl}-2 / \mathrm{Bcl}-\mathrm{xL}$ in different cancer cells, such as human breast adenocarcinoma cell, HeLa cell and prostate cancer cell lines $[16,30,31]$. In this study, the dissociation of the Beclin 1-Bcl-xL complex by AT-101 was also confirmed in A549 cells. Moreover, autophagy can be regulated by many factors and signaling pathways. Within the complex regulation of autophagy, the mammalian target of rapamycin (mTOR) is considered to be the central regulator of autophagy. Several studies have shown that gossypol is characterized by the inhibition of mTOR signaling, which probably occurs upstream of the Beclin 1-Bcl-2/Bcl-xL complexes [16, 17]. Consistently, our results also found that the autophagy induced AT-101 was associated with inhibition of mTOR pathway in A549 lung cancer cell line. It is found that autophagy can be activated as the cellular response to cancer therapy. And inhibition of autophagy sensitizes cancer cells to a number of therapeutic modalities, including chemotherapy, radiotherapy, hormonal therapy and receptor tyrosine kinase inhibition. By using pharmacological autophagy inhibitor and knockdown of autophagy essential genes we also found that blockage of autophagy greatly enhanced the growth inhibitory effect of AT-101. Thus, inhibition of autophagy may have the potential to improve the clinical efficacy of AT-101 for non-small cell lung cancer.

In summary, our research demonstrated that AT-101 could induce apoptosis and cytoprotective autophagy in A549 lung cancer cell and inhibition of AT-101-induced autophagy greatly promoted apoptotic cell death. Thus, a new therapeutic paradigm to inhibit autophagy in combination with efforts to enhance apoptosis through targeting the Bcl-2 family of proteins represents a promising approach with higher efficacy for NSCLC patients.

Acknowledgements: This study was funded by the Natural Science Foundation of Hubei Province of China (grant no. 2012FFB02328).

\section{References}

[1] SPIRO SG, TANNER NT, SILVESTRI GA, JANES SM, LIM E et al. Lung cancer: progress in diagnosis, staging and therapy. Respirology 2010; 15: 44-50. http://dx.doi.org/10.1111/j.1440$\underline{1843.2009 .01674 . \mathrm{x}}$

[2] CORY S, ADAMS JM The Bcl2 family: regulators of the cellular life-or-death switch. Nat Rev Cancer 2002; 2: 647-656. http://dx.doi.org/10.1038/nrc883
[3] KANG M, Reynolds CP Bcl-2 inhibitors: Targeting mitochondrial apoptotic pathways in cancer therapy. Clin Cancer Res 2009; 15: 1126-1132. http://dx.doi.org/10.1158/1078-0432. CCR-08-0144

[4] DANIAL NN BCL-2 family proteins: Critical checkpoints of apoptotic cell death. Clin Cancer Res 2007; 13: 7254-7263. http://dx.doi.org/10.1158/1078-0432.CCR-07-1598

[5] WESARG E, HOFFARTH S, WIEWRODT R, KROLL M, BIESTERFELD $S$ et al. Targeting BCL-2 family proteins to overcome drug resistance in non-small cell lung cancer. Int J Cancer 2007; 121: 2387-2394. http://dx.doi.org/10.1002/ ijc. 22977

[6] ZHANG H, GUTTIKONDA S, ROBERTS L, UZIEL T, SEMIZAROV D et al. Mcl-1 is critical for survival in a subgroup of non-small-cell lung cancer cell lines. Oncogene 2011; 30: 1963-1968. http://dx.doi.org/10.1038/onc.2010.559

[7] WOLTER KG, WANG SJ, HENSON BS, WANG S, GRIFFITH KA et al. (-)-gossypol inhibits growth and promotes apoptosis of human head and neck squamous cell carcinoma in vivo. Neoplasia 2006; 8: 163-172. http://dx.doi.org/10.1593/ neo.05691

[8] KLINE MP, RAJKUMAR SV, TIMM MM, KIMLINGER TK, HAUG JL et al. R-(-)-gossypol (AT-101) activates programmed cell death in multiple myeloma cells. Exp Hematol 2008; 36: 568-576. http://dx.doi.org/10.1016/j.exphem.2008.01.003

[9] BALAKRISHNAN K, WIERDA WG, KEATING MJ, GANDHI V GOSSYPOL, a BH3 mimetic, induces apoptosis in chronic lymphocytic leukemia cells. Blood 2008; 112: 1971-1980. http://dx.doi.org/10.1182/blood-2007-12-126946

[10] CHEONG H, LU C, LINDSTEN T, THOMPSON CB Therapeutic targets in cancer cell metabolism and autophagy. Nat Biotechnol 2012; 30: 671-678. http://dx.doi.org/10.1038/ nbt.2285

[11] MEILER J, SCHULER M Therapeutic targeting of apoptotic pathways in cancer. Curr Drug Targets 2006; 7: 1361-1369. http://dx.doi.org/10.2174/138945006778559175

[12] PATTINGRE S, LEVINE B Bcl-2 inhibition of autophagy: a new route to cancer? Cancer Res 2006; 66: 2885-2888. http://dx.doi.org/10.1158/0008-5472.CAN-05-4412

[13] LUO S, RUBINSZTEIN DC Atg 5 and Bcl-2 provide novel insights into the interplay between apoptosis and autophagy. Cell Death Differ 2007; 14: 1247-1250. http://dx.doi.org/10.1038/ sj.cdd. 4402149

[14] BARAKAT K, GAJEWSKI M, TUSZYNSKI JA DNA repair inhibitors: the next major step to improve cancer therapy. Curr Top Med Chem 2012; 12: 1376-1390. http://dx.doi. org/10.2174/156802612801319070

[15] WARR MR, SHORE GC Small-molecule Bcl-2 antagonists as targeted therapy in oncology. Curr Oncol 2008; 15: 256-261. http://dx.doi.org/10.3747/co.v15i6.392

[16] GAO P, BAUVY C, SOUQUERE S, TONELLI G, LIU L et al. The Bcl-2 homology domain 3 mimetic gossypol induces both Beclin 1-dependent and Beclin 1-independent cytoprotective autophagy in cancer cells. J Biol Chem 2010; 285: 25570-25581. http://dx.doi.org/10.1074/jbc.M110.118125

[17] MEHRPOUR M, ESCLATINE A, BEAU I, CODOGNO P Autophagy in health and disease. 1. Regulation and significance 
of autophagy: an overview. Am J Physiol Cell Physiol 2010; 298: 776-785. http://dx.doi.org/10.1152/ajpcell.00507.2009

[18] KREUZALER P, WATSON CJ Killing a cancer: what are the alternatives? Nat Rev Cancer 2012; 12: 411-424. http://dx.doi. org/10.1038/nrc3264

[19] COTTER TG Apoptosis and cancer: the genesis of a research field. Nat Rev Cancer 2009; 9: 501-507. http://dx.doi.org/ $10.1038 / \mathrm{nrc} 2663$

[20] KROEMER G, GALLUZZI L, BRENNER C Mitochondrial membrane permeabilization in cell death. Physiol Rev 2007; 87: 99-163. http://dx.doi.org/10.1152/physrev.00013.2006

[21] WILLIS SN, FLETCHER JI, KAUFMANN T, VAN DELFT MF, $\mathrm{CHEN} \mathrm{L}$ et al. Apoptosis initiated when $\mathrm{BH} 3$ ligands engage multiple Bcl-2 homologs, not bax or bak. Science 2007; 315: 856-859. http://dx.doi.org/10.1126/science.1133289

[22] CHEN L, WILLIS SN, WEI A, SMITH BJ, FLETCHER JI et al. Differential targeting of prosurvival Bcl-2 proteins by their $\mathrm{BH} 3$-only ligands allows complementary apoptotic function. Mol Cell 2005; 17: 393-403. http://dx.doi.org/10.1016/ j.molcel.2004.12.030

[23] STRASSER A, HARRIS AW, JACKS T, CORY S DNA damage can induce apoptosis in proliferating lymphoid cells via p53independent mechanisms inhibitable by bcl-2. Cell 1994; 79: 329-339. http://dx.doi.org/10.1016/0092-8674(94)90201-1

[24] SCHMITT CA, ROSENTHAL CT, LOWE SW Genetic analysis of chemoresistance in primary murine lymphomas. Nat Med 2000; 6: 1029-1035. http://dx.doi.org/10.1038/79542

[25] KAUFMANN SH, VAUX DL Alterations in the apoptotic machinery and their potential role in anticancer drug resistance.
Oncogene 2003; 22: 7414-7430. http://dx.doi.org/10.1038/ si.onc. 1206945

[26] ZANGEMEISTER-WITTKE U, LEECH SH, OLIE RA, SIMOES-WUST AP, GAUTSCHI O et al. A novel bispecific antisense oligonucleotide inhibiting both bcl-2 and bcl-xL expression efficiently induces apoptosis in tumor cells. Clin Cancer Res 2000; 6: 2547-2555.

[27] RUDIN CM, KOZLOFF M, HOFFMAN PC, EDELMAN MJ, KARNAUSKAS R et al. Phase I study of G3139, a bcl-2 antisense oligonucleotide, combined with carboplatin and etoposide in patients with small-cell lung cancer. J Clin Oncol 2004; 22: 1110-1117. http://dx.doi.org/10.1200/JCO.2004.10.148

[28] KLASA RJ, GILLUM AM, KLEM RE, FRANKEL SR Oblimersen Bcl-2 antisense: facilitating apoptosis in anticancer treatment. Antisense Nucleic Acid Drug Dev 2002; 12: 193-213. http://dx.doi.org/10.1089/108729002760220798

[29] READY N, KARASEVA NA, ORLOV SV, LUFT AV, POPOVYCH O et al. Double-Blind, Placebo-Controlled, Randomized Phase 2 Study of the Proapoptotic Agent AT-101 Plus Docetaxel, in Second-Line Non-small Cell Lung Cancer. J Clin Oncol 2011; 6: 781-785]

[30] HUANG S, SINICROPE FA Celecoxib-induced apoptosis is enhanced by ABT-737 and by inhibition of autophagy in human colorectal cancer cells. Autophagy 2010; 6: 256-269. http://dx.doi.org/10.4161/auto.6.2.11124

[31] SALEEM A, DVORZHINSKI D, SANTANAM U, MATHEW $\mathrm{R}, \mathrm{BRAY} \mathrm{K}$ et al. Effect of dual inhibition of apoptosis and autophagy in prostate cancer. Prostate 2012; 72: 1374-1381. http://dx.doi.org/10.1002/pros.22487 